\title{
Stimulating Denitrification in a Marine Recirculating Aquaculture System Biofilter Using Granular Starch as a Carbon Source
}

\author{
Megan M. Morrison ${ }^{1,2}$, Yossi Tal1 ${ }^{1}$ and Harold J. Schreier*1,2 \\ ${ }^{1}$ Center of Marine Biotechnology \\ University of Maryland Biotechnology Institute \\ 701 E. Pratt Street, Baltimore, MD 21202 \\ ${ }^{2}$ Department of Biological Sciences \\ University of Maryland Baltimore County \\ 1000 Hilltop Circle, Baltimore, MD 21250 \\ *Corresponding author: Schreier@umbi.umd.edu
}

\begin{abstract}
Keywords: Fixed bed biofilter, heterotrophic denitrification, moving bed bioreactor
\end{abstract}

\section{ABSTRACT}

Maintaining superior water quality in intensive recirculating aquaculture systems (RAS) by controlling levels of inorganic nitrogenous wasteammonia, nitrate and nitrite-derived from uneaten food and fecal excretion is often a challenge. In most systems, solids are removed mechanically and ammonia is oxidized to nitrate by nitrifying biological filtration; nitrate is subsequently eliminated through numerous water exchanges. Alternatively, nitrate removal is achieved using a bacterialmediated denitrification component that reduces nitrate to nitrogen gas under anoxic conditions, a process that depends on the application of external or endogenous electron and carbon donors, e.g. carbohydrates or organic alcohols. In this study, we compared the capacity of acetate, glucose, soluble starch, and granular starches to promote the denitrifying activity of heterotrophic bacteria in biofilm-coated polyethylene beads

International Journal of Recirculating Aquaculture 9 (2008) 23-41. All Rights Reserved (C) Copyright 2008 by Virginia Tech, Blacksburg, VA USA 
from a marine RAS moving bed bioreactor (MBB) under anaerobic conditions. Granular starches (corn, wheat, and rice) were as effective as glucose in supporting denitrification, and were 7.6 and 9.8 times more effective in removing nitrate when compared to soluble starch and acetate, respectively. Furthermore, granular starches retained their denitrification potential for longer time periods than soluble starch or acetate. The low cost, ease of use, and non-toxic nature of granular starches make them an ideal exogenous carbon source for promoting denitrification in RAS bioreactors.

\section{INTRODUCTION}

Recirculating aquaculture systems (RAS) have become an attractive approach for farming fish due to their advantage in providing high yields of fish stock, as well as their capacity to be both biosecure and environmentally sustainable (Tal et al. 2009, Zohar et al. 2005). Because the success of commercial aquaculture depends on creating an environment optimized for rapid growth, one of the benefits of using a semi-closed culture unit is the manageability of water parameters that influence fish health and growth rate densities (Cytryn et al. 2003, Timmons et al. 2002, Zohar et al. 2005). At the same time, a major drawback of RAS stems from significant loading of organic matter derived from uneaten food and fecal excretion, which leads to oxygen depletion and the accumulation of toxic nitrogen compounds such as ammonia and nitrite (Prinsloo et al. 1999, van Rijn 1996). As part of the remedy for these problems, solid wastes are usually removed by mechanical filtration or sedimentation. In addition, RAS incorporate biological filtration that includes nitrification to remove toxic inorganic nitrogen. This microbe-driven process oxidizes ammonia to nitrite and, subsequently, nitrate, under aerobic conditions (Timmons et al. 2002, van Rijn and Rivera 1990). To alleviate the threat of low oxygen levels, oxygen is pumped directly into the culture chamber and heavy aeration is employed to ensure nitrifying bacteria receive ample oxygen to support their oxidizing activity (Timmons et al. 2002).

A major challenge faced by industry is the need for a mechanism to manage the accumulation of nitrate that occurs in recirculating systems as water exchange rates are reduced (van Rijn et al. 2006, Zohar et al. 2005). However, studies focusing on nitrate removal have been few, 
primarily because high nitrate concentrations have not been considered to directly impact most cultured organisms. Still, control of nitrate levels is warranted, since fish have been shown to suffer from nitrate stress (Burgess 1995, Grguric et al. 2000, Hrubec et al. 1996). Additionally, waste management and disposal have become increasingly important due to increases in the stringency of environmental regulations (Costa-Pierce and Desbonnet 2005, White et al. 2004).

Successful removal of nitrate from wastewater has been achieved by the inclusion of biological denitrification, an anaerobic process that reduces nitrate to nitrogen gas. The process requires a suitable electron donor to fuel the heterotrophic activity as a carbon and energy source (Gomez et al. 2000, Grguric et al. 2000, Lee and Welaner 1996, van Rijn et al. 2006). Denitrification of industrial wastewater containing high nitrate (>1000 mg-N/l influent) has been accomplished using an activated sludge process (Glass and Silverstein 1999, Labelle et al. 2005, Mycielski et al. 1983) and van Rijn and Rivera (1990) attempted a similar nitrate reduction treatment by moving organic matter derived from uneaten feed and fish waste from an intensive RAS tank through a denitrifying fluidized bed reactor. Performance of this system, however, suggested that carbon limitation was a likely factor underlying the low denitrification rates (Arbiv and van Rijn 1995).

Because the concentration of available carbon sources in RAS may be insufficient to sustain nitrate removal, an external source must be supplied (Isaacs et al. 1994, Phillips and Love 1998). Chemostat experiments demonstrated that activated sludge could yield comparatively high denitrification rates (from 26-76 $\mathrm{mg} \mathrm{NO}_{3}-\mathrm{N} / \mathrm{g} \mathrm{TSS} / \mathrm{h}$ ) when fed with carbon sources including hydrolyzed starch, methanol, acetic acid and crude syrup (Lee and Welaner 1996). Chen et al. (1991) supplied a combined nitrification loop and denitrifying submerged bioreactor with excess methanol in long-term continuous cultivation to completely reduce 200-1000 mg $\mathrm{NO}_{2}-\mathrm{N} / 1$. Similarly, in a study using a submerged filter to remove nitrate from groundwater, ethanol and methanol were found to be more effective than sucrose when added to treat groundwater containing $100 \mathrm{mg} \mathrm{NO}$-N/1 (Gomez et al. 2000).

In previous studies we observed that nitrifying biofilters from marine RAS filter systems harboring different organic loads exhibited differing potential for carrying out nitrogenous transformations. We found that 
filters with high organic load levels demonstrated a denitrification capacity in the absence of an external carbon source, while adding acetate could stimulate denitrifying activity for the low organic load (Tal et al. 2003). In the present study, we evaluated the effectiveness of soluble and granular carbon sources in stimulating denitrification activity of heterotrophic bacteria associated with both intensive (high load) and relatively low intensive (low load) marine RAS biofilters. Carbon sources were selected based on their complexity and molecular weight, as it has been shown that simple carbon compounds favor biological nitrogen removal over those with more complex molecular structures (Gomez et al. 2000, Hallin and Pell 1998, Peng et al. 2007), and that the molecular weight of a carbon source significantly influenced denitrification efficiency (Her and Huang 1995). We found that granular starches (corn, wheat, and rice) were as effective in supporting denitrification as glucose and acetate, and furthermore, maintained significant potential for nitrate removal long after acetate and soluble starch.

\section{MATERIALS AND METHODS}

\section{Laboratory-Scale Experiments}

Batch experiments were performed using polyethylene beads removed from "high" (8-10 mg dry organic matter/bead; initial $\mathrm{O}_{2}$ consumption rate of $0.9 \mathrm{mg} \mathrm{O} / 1 / \mathrm{min} /$ bead) and "low" organic load (2-4 mg dry organic matter/bead; initial $\mathrm{O}_{2}$ consumption rate of $0.4 \mathrm{mg} \mathrm{O} / 1 / \mathrm{min} /$ bead) marine recirculating nitrifying moving-bed biofilter (MBB) systems (Tal et al. 2003). High-load filter beads were obtained from a $2 \mathrm{~m}^{3}$ aerobic nitrifying MBB filled with a bead volume of $1 \mathrm{~m}^{3}$. The aerobic MBB linked two 4.2 $\mathrm{m}^{3}$ tanks containing 10-20 kg/m $\mathrm{m}^{3}$ of gilthead seabream, Sparus aurata, and a $0.3 \mathrm{~m}^{3}$ anaerobic cylindrical denitrification tank, densely packed with $0.2 \mathrm{~m}^{3}$ of polyethylene beads having a specific surface area of 500 $\mathrm{m}^{2} / \mathrm{m}^{3}$. The system was maintained with a salinity of $17 \mathrm{ppt}$ and was operated as described previously (Tal et al. 2003). Low organic load filter beads were collected from a separate nitrification MBB unit that was connected to a large $10.5 \mathrm{~m}^{3}$ culture tank holding a variety of marine fish at stock density of approximately $5 \mathrm{~kg} / \mathrm{m}^{3}$.

Under anaerobic conditions and in the presence of $200 \mathrm{mg} \mathrm{NO}_{3}^{-}-\mathrm{N} / \mathrm{ml}$, beads were incubated at room temperature until they were no longer capable of reducing additional nitrate applications, indicating that all 
endogenous organic sources were depleted. At this point, corn, wheat, and rice starches, soluble starch, glucose, and (potassium) acetate were added to evaluate their ability to independently stimulate denitrification. Biofilter beads (170) from the low organic load biofilter system were partitioned into $200 \mathrm{ml}$ capped roller tubes containing synthetic saltwater media (Tal et al. 2003) at pH 7.0 - 7.5 and supplemented with a carbon source at a final concentration of $2.7 \mathrm{mg}$ carbon source/ml with $150 \mathrm{mg} \mathrm{NO}-\mathrm{N} / \mathrm{l}$. Under these conditions, carbon to nitrogen $(\mathrm{C}: \mathrm{N})$ ratios at the start of each experiment were 8:1 for each carbon source. The high organic load bead samples were treated in the same manner and each condition was done in duplicate. All sample solutions were flushed with nitrogen gas and tubes were immediately incubated at room temperature and rotated continuously at $10 \mathrm{rev} / \mathrm{min}$ in an Amersham Hybridization Oven/Shaker (GE Healthcare, Amersham Biosciences, Pittsburgh, PA, USA).

\section{Sampling Procedure and Analysis}

During the course of incubation, $1 \mathrm{ml}$ samples were removed from each tube, centrifuged at $12,000 \mathrm{x} g$ for 5 minutes and concentrations of nitrite, nitrate, total carbon (TC), and total available carbon (TAC) were determined in supernatant fractions. Periodic adjustments were made with additions of $\mathrm{NaOH}$ to maintain $\mathrm{pH}$ within a range of 7.0 - 7.5. All measurements were done in duplicate within 24 hours of collection, or when not analyzed immediately, after storage at $4^{\circ} \mathrm{C}$. Nitrite and nitrate concentrations were determined as described by Tal et al. (2003). TAC and TC measurements of starch solutions were determined using the anthrone reagent as described previously (Tal et al. 1999). Statistical analyses for nitrate consumption rates were determined within the linear portions of the graphs (correlation coefficient $>0.9$ ) using the LINEST least squares method in Excel X for Mac (Microsoft, Redmond, WA, USA).

\section{RESULTS}

\section{Effect of Carbon Source on Denitrification Potential of Low-Load Beads}

To examine the ability of individual carbon sources to stimulate denitrification, low-load beads were incubated under anoxic conditions in the presence of nitrate $(150 \mathrm{mg} / \mathrm{l})$ to promote complete utilization of 
Stimulating denitrification in a marine RAS using granular starch

Figure 1. Nitrate removal activity of low-load beads in the presence of various carbon sources. The initial nitrate and carbon source concentrations were 150 $\mathrm{mg} \mathrm{NO}_{3}$ - $\mathrm{N} / \mathrm{l}$ and $2.7 \mathrm{mg} / \mathrm{ml}$, respectively. Nitrate utilization is expressed as the percentage of initial nitrate concentration $\left(\%\left[\mathrm{NO}_{3^{-}}\right]_{i}\right)$ that remained at each time point sampled.
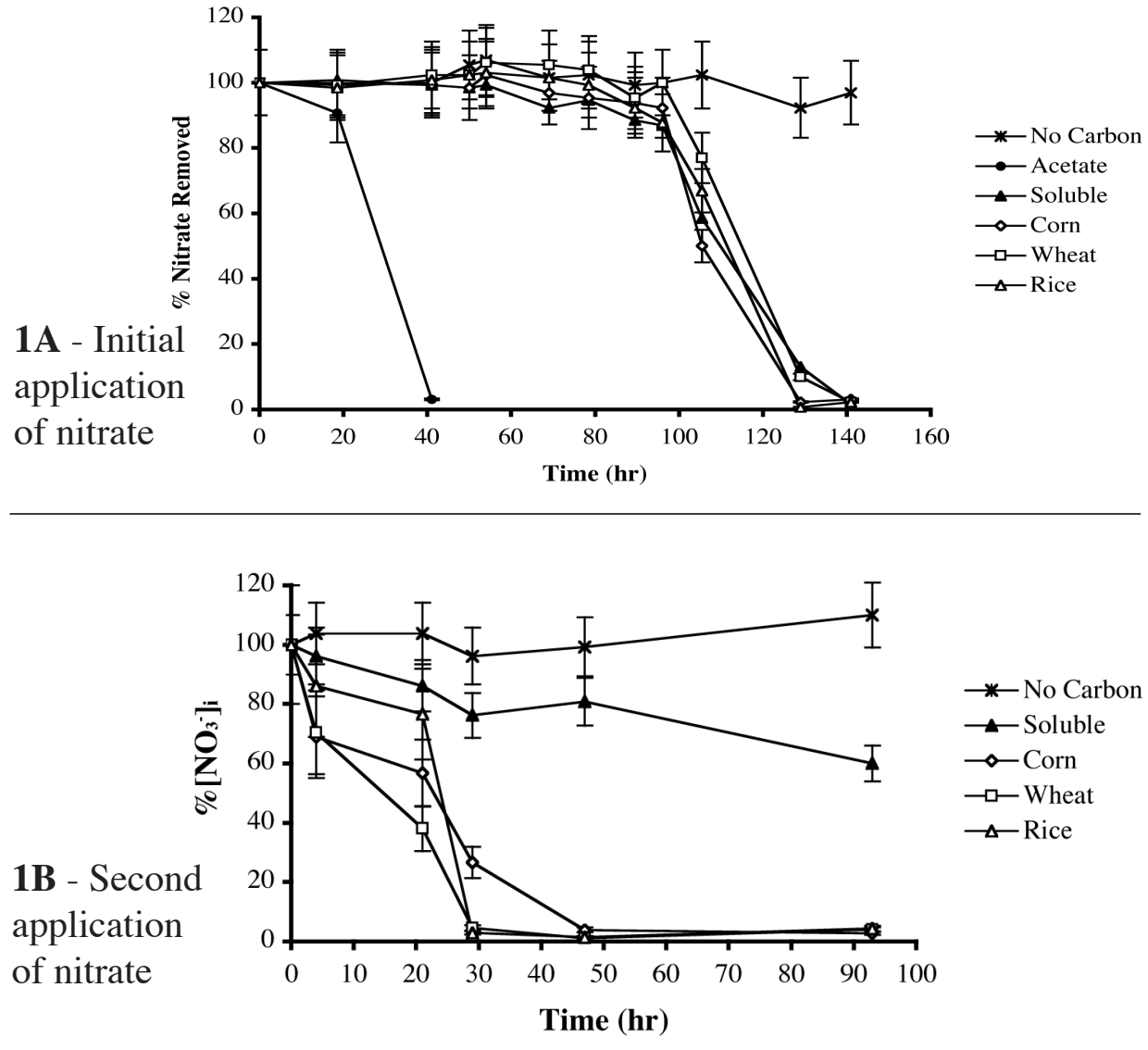

1C - Third application of nitrate

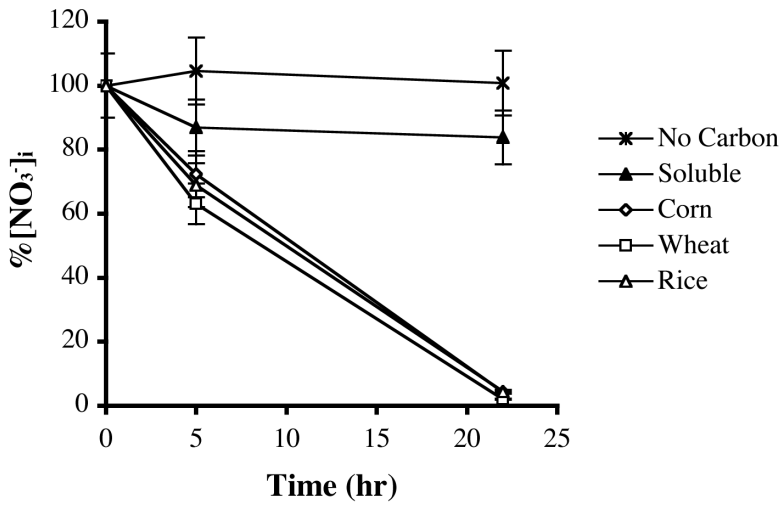


endogenous carbon sources. Under these conditions, nitrate removal by denitrifying heterotrophs established within the nitrifying community was stimulated after several days of incubation under anaerobic conditions (Tal et al. 2003). Once the ability to metabolize nitrate could no longer be detected (as determined by the absence of measurable nitrateremoving activity), beads were distributed equally into roller tubes and nitrate removal was measured after addition of acetate, soluble starch, and granular corn, wheat and rice starches. Compared to control (no carbon source addition), all carbon sources were found to support nitrate utilization (Figure 1A). With the exception of acetate, which stimulated nitrate utilization within approximately 20 hours after its addition, significant decreases in nitrate concentrations were detected 90 to 100 hours after carbon source addition. The delay in nitrate-removing activity likely reflected a difference in the availability of simple and complex soluble and insoluble carbohydrates for use as reducing agents. Once nitrate utilization occurred, nitrate removal rates were found to vary between 2.5 and $5.4 \mathrm{mg} \mathrm{NO}_{3}-\mathrm{N} / \mathrm{l} / \mathrm{hr}$, with acetate providing the greatest activity (Table 1).

Table 1. Nitrate removal rates for low-and high-load beads in the presence of the various carbon sources ${ }^{a}$.

\begin{tabular}{|c|c|c|c|c|c|c|}
\hline \multirow{2}{*}{$\begin{array}{l}\text { Carbon } \\
\text { source }\end{array}$} & \multicolumn{3}{|c|}{$\begin{array}{c}\text { Low-Load Beads } \\
\text { NO }_{3^{-}} \text {removal }\left(\mathrm{mg} \mathrm{NO}_{3-\mathrm{N}} \mathrm{N} / \mathrm{l} / \mathrm{hr}\right)\end{array}$} & \multicolumn{3}{|c|}{$\begin{array}{c}\text { High-Load Beads } \\
\mathrm{NO}_{3}-\text { removal }\left(\mathrm{mg} \mathrm{NO}{ }_{3}-\mathrm{N} / \mathrm{l} / \mathrm{hr}\right)\end{array}$} \\
\hline & $\begin{array}{l}\text { 1st } \mathrm{NO}_{3-} \\
\text { Addition }\end{array}$ & $\begin{array}{l}1 \text { st } \mathrm{NO}_{3-} \\
\text { Addition }\end{array}$ & $\begin{array}{l}1 \text { st } \mathrm{NO}_{3-} \\
\text { Addition }\end{array}$ & $\begin{array}{l}\text { 1st } \mathrm{NO}_{3-} \\
\text { Addition }\end{array}$ & $\begin{array}{l}\text { 1st } \mathrm{NO}_{3-} \\
\text { Addition }\end{array}$ & $\begin{array}{l}1 \mathrm{st} \mathrm{NO}_{3-} \\
\text { Addition }\end{array}$ \\
\hline Acetate & $5.4 \pm 0.1$ & $\mathrm{ND}^{\mathrm{b}}$ & ND & $8.5 \pm 1.7$ & $13.6 \pm 3.2$ & $1.1 \pm 0.2$ \\
\hline Glucose & ND & ND & ND & $10.2 \pm 2.0$ & $9.5 \pm 1.5$ & $10.9 \pm 2.2$ \\
\hline $\begin{array}{l}\text { Soluble } \\
\text { Starch }\end{array}$ & $2.5 \pm 0.2$ & $\begin{array}{l}0.61 \pm \\
0.03\end{array}$ & $\begin{array}{c}0.84 \pm \\
0.21\end{array}$ & ND & ND & ND \\
\hline $\begin{array}{l}\text { Wheat } \\
\text { Starch }\end{array}$ & $3.5 \pm 0.4$ & $3.8 \pm 0.8$ & $6.4 \pm 1.1$ & $5.6 \pm 0.8$ & $10.7 \pm 3.1$ & $9.1 \pm 1.8$ \\
\hline $\begin{array}{l}\text { Rice } \\
\text { Starch }\end{array}$ & $3.6 \pm 0.4$ & $4.4 \pm 0.7$ & $6.3 \pm 0.7$ & $3.6 \pm 0.7$ & $10.7 \pm 2.1$ & $10.6 \pm 2.1$ \\
\hline Starch & $3.7 \pm 0.5$ & $2.8 \pm 0.5$ & $6.4 \pm 0.4$ & $4.2 \pm 0.9$ & $11.1 \pm 3.0$ & $10.8 \pm 2.0$ \\
\hline
\end{tabular}

${ }^{a}$ Nitrate removal rates were calculated using the linear portions (displaying a correlation coefficient >0.9) of the graphs from Figures 1 (low-load beads) and 3 (high-load beads).

${ }^{b} \mathrm{ND}$; not determined. 
$\mathbf{2 A}$ -

Low-load beads
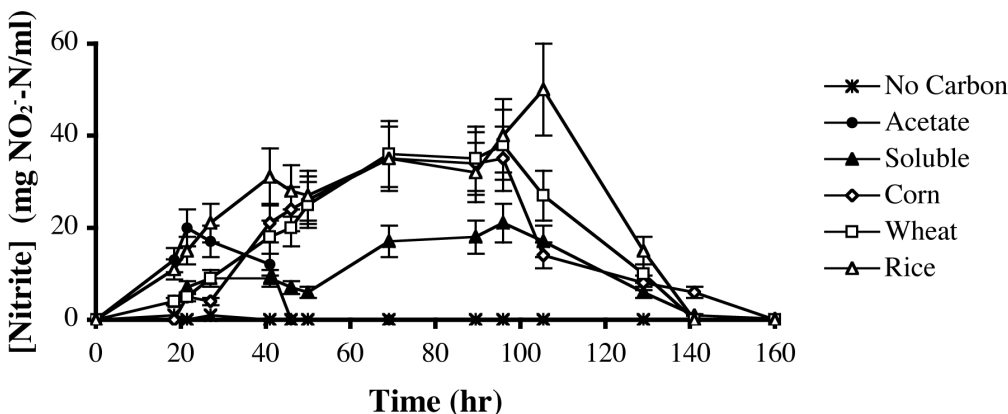

Time (hr)

2B -

High-load beads

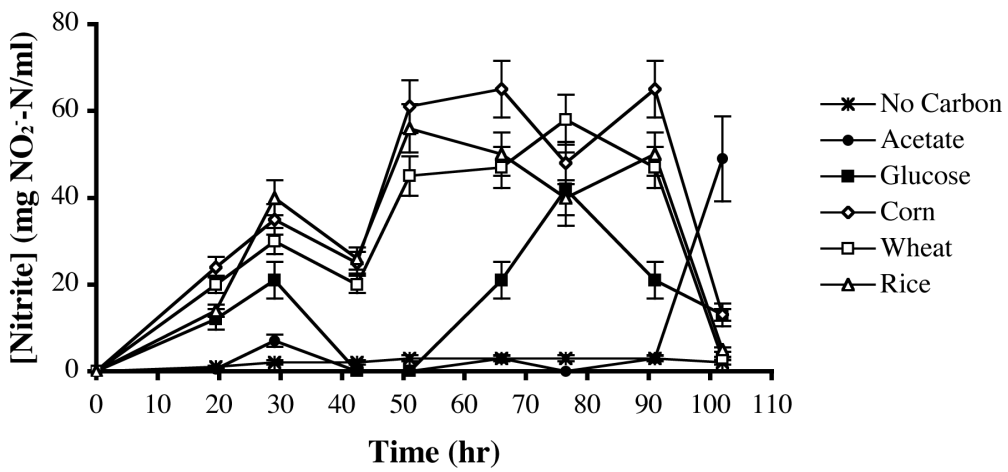

Figure 2. Nitrite removal activity of beads in the presence of various carbon sources. Low-load (A) and high-load (B) beads were treated with an initial nitrate concentration of $150 \mathrm{mg} \mathrm{NO}_{3}-\mathrm{N} / \mathrm{l}$. Carbon sources were added at a final concentration of $2.7 \mathrm{mg} / \mathrm{ml}$.

For all treatments (except control), nitrite levels were found to gradually accumulate-rising to their highest levels near the time that nitrate consumption could be detected-and then decreasing to undetectable levels at a time that was nearly coincidental with complete nitrate utilization (Figure 2A). For acetate, nitrite levels were highest (20 mg $\left.\mathrm{NO}_{2}-\mathrm{N} / \mathrm{l}\right) 21$ hours after acetate addition and decreased to undetectable levels after nitrate was completely utilized. Similarly, 96 hours after addition of the other carbon sources, nitrite levels peaked between 35 and $50 \mathrm{mg} \mathrm{NO}{ }_{2}-\mathrm{N} / 1$ in the presence of granular corn, wheat, and rice starches and $21 \mathrm{mg} \mathrm{NO} \mathrm{N}_{2} \mathrm{~N} / 1$ for soluble starch (Figure 2A). At 106 hours, or near the time when nitrate concentrations began to decrease (Figure 1A), nitrite levels also declined and completely disappeared after all nitrate 
was utilized (Figure 2A). Nitrite could not be detected at any time in tubes that were not supplemented with carbon source (control).

After nitrate levels decreased below detection limits, TAC measurements of incubations supplemented with soluble and granular starches indicated the absence of measurable soluble carbohydrates (data not shown). To assess remaining denitrification potential in the absence of additional carbon source application, a second dose of nitrate (150 mg NO $\left.\mathrm{m}_{3}-\mathrm{N} / \mathrm{l}\right)$ was placed into each tube and nitrate levels were monitored. As shown in Figure 1B, nitrate consumption occurred shortly after the second nitrate treatment in beads supplemented with the granular starches at rates between 2.8 to $4.4 \mathrm{mg} \mathrm{NO}_{3}-\mathrm{N} / \mathrm{l} / \mathrm{hr}$ (Table 1 ), which were similar to those observed for the first dose of nitrate, and nearly complete nitrate removal was observed between 30 to 50 hours post-application (Figure 1B). Beads supplemented with soluble starch, on the other hand, exhibited a 4.2-fold decrease in nitrate utilization activity compared to the first dose, and approximately $60 \%$ of the second dose of nitrate remained 90 hours postaddition (Figure 1B). Consumption of nitrate by the acetate-supplemented tubes could not be detected (data not shown). A third treatment of nitrate (150 mg NO$-\mathrm{N} / \mathrm{l})$ resulted in nitrate removal patterns for granular starches that were similar to those obtained for the second dose (Figure 1C) although consumption rates were nearly two times greater than those obtained for the first nitrate application (Table 1). Nitrate-removing activity for the soluble starch-supplemented beads in the third nitrate treatment was minimal (Figure $1 \mathrm{C}$ and Table 1) and similar to the activity observed after the second addition (Figure 1B).

\section{Denitrification Potential of High-Load Beads with Added Carbon Source}

The denitrification activity of beads from a high-load filtration system were examined in the same manner as the low-load beads (Figure 3). As was observed for the low-load beads, all carbon source supplements were capable of stimulating nitrate removal. After an approximate 20-30 hr delay, acetate and glucose yielded nearly $100 \%$ removal approximately 40 hours after their addition, at rates of $8.5 \pm 1.7$ and $10.2 \pm 2.0 \mathrm{mg}$ $\mathrm{NO}_{3}-\mathrm{N} / \mathrm{l} / \mathrm{hr}$, respectively. In the presence of the granular starches, nitrate levels started to decrease between 40 to 75 hours after carbon source addition-25 to 60 hours earlier than observed for the low-load beads (compare Figures 1A and 3A), - with maximum removal rates between 
Stimulating denitrification in a marine RAS using granular starch

3A - Initial application of nitrate

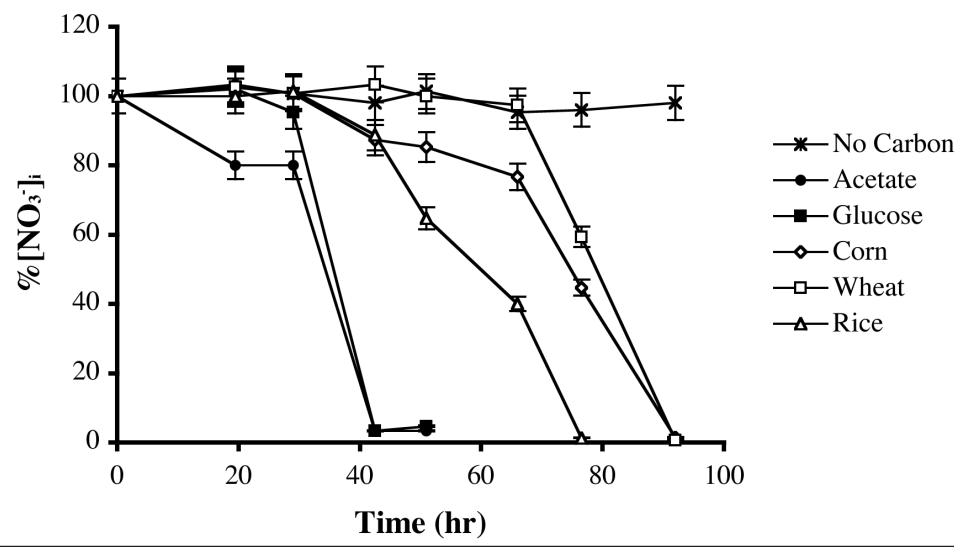

3B - Second application of nitrate

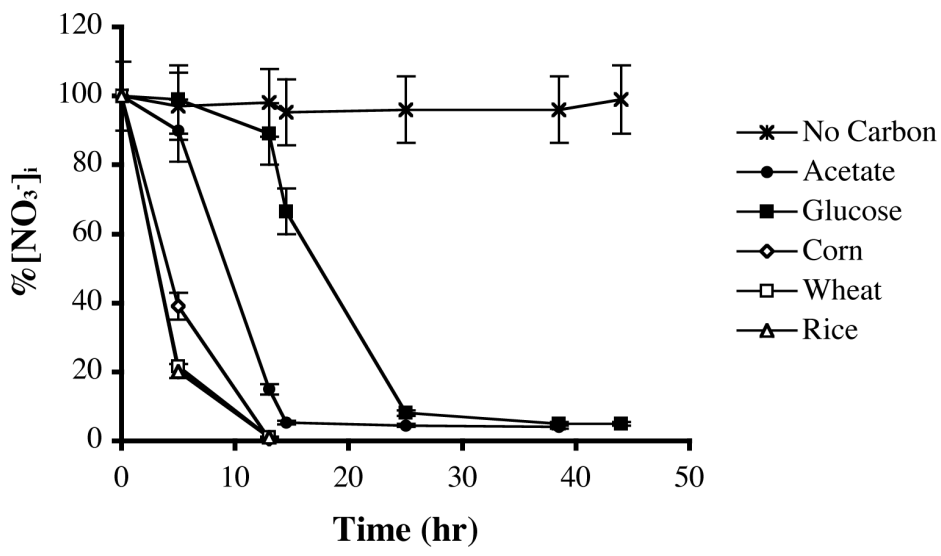

3C - Third application of nitrate

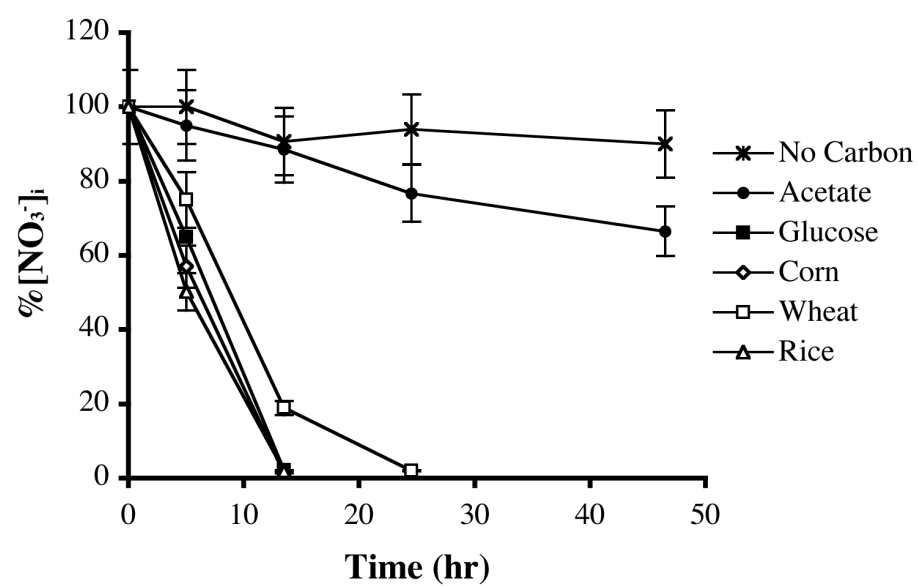

Figure 3. Nitrate removal activity of high-load beads in the presence of various carbon sources. The initial nitrate and carbon source concentrations were 150 $\mathrm{mg} \mathrm{NO}{ }_{3}-\mathrm{N} / \mathrm{l}$ and $2.7 \mathrm{mg} / \mathrm{ml}$, respectively. Nitrate utilization is expressed as the percentage of initial nitrate concentration $\left(\%\left[\mathrm{NO}_{3}^{-}\right]_{i}\right)$ that remained at each time point sampled. 
approximately 3.6 and $5.6 \mathrm{mg} \mathrm{NO}-\mathrm{N} / \mathrm{l} / \mathrm{hr}$, which were similar to those observed for the low-load beads (Table 1).

Nitrite levels for high-load beads supplemented with granular starch exhibited patterns very similar to those found for the low-load bead experiments (Figure 2B). Levels gradually increased to as much as 65 $\mathrm{mg} \mathrm{NO}-\mathrm{N} / 1$ from 50 to 70 hours post nitrate addition for the granular starches and only 7 and $23 \mathrm{mg} \mathrm{NO}-\mathrm{N} / 1$ for acetate and glucose, respectively, 29 hours after nitrate addition. Within 10-15 hours after reaching their maximal levels, nitrite concentrations in the presence of each carbon source decreased to their lowest levels (Figure 2B), in parallel with nitrate consumption. Nitrite could not be detected at any time in tubes with beads lacking a carbon source (Figure 3A).

After nitrate concentrations decreased below the level of detection, nitrate (150 $\mathrm{mg} \mathrm{NO}$-N/l) was added to each tube to assess residual denitrification potential of the high-load beads. As can be seen in Figure 3B, nitrate removal in incubations supplemented with granular starches occurred without significant delay, with all nitrate utilized within 12 hours postaddition at a rate of approximately $11 \mathrm{mg} \mathrm{NO}_{3}-\mathrm{N} / \mathrm{l} / \mathrm{hr}$ (Table 1) - almost 3 times faster than their activities during the initial nitrate addition. On the other hand, nitrate removal for acetate and glucose-supplemented tubes was delayed almost 20 and 40 hours, respectively, and maximum removal rates were similar to those observed after the first nitrate addition (Table 1). After 70 hours - the point at which nitrate concentrations were no longer detectable (Figure 3B) - each tube received a third application of nitrate $\left(150 \mathrm{mg} \mathrm{NO}_{3}-\mathrm{N} / \mathrm{l}\right)$. Beads treated with glucose and the three granular starches continued to show nitrate removal activity that was comparable to the second nitrate application in both appearance and removal rates (Figure 3C and Table 1). Acetate-supplemented beads, on the other hand, exhibited a marked decrease in their ability to support significant denitrification activity, with a nitrate removal rate that was 12.4-fold lower than that observed for the second dose, suggesting that acetate was no longer available as a carbon source to support this process (Figure 3C).

Unlike the pattern of activity observed with the first nitrate addition, nitrite levels examined in the granular starch-supplemented tubes remained very low after the second dose of nitrate and did not rise to levels greater than $15 \mathrm{mg} \mathrm{NO}$ - $\mathrm{N} / 1$ (not shown). On the other hand, 
the decreased ability of the glucose-supplemented filter to support denitrification was reflected in the accumulation of nitrite levels that exceeded $40 \mathrm{mg} \mathrm{NO}-\mathrm{N} / 1$, which declined to near undetectable levels only after complete exhaustion of nitrate at 70 hours (not shown).

\section{DISCUSSION}

Wastewater treatment systems that rely on activated sludge or submerged filters often require addition of suitable carbon sources such as ethanol, methanol, or acetate in order to enhance nitrate removal (Lee and Welaner 1996, Stief 2001). Using these carbon sources to stimulate denitrification, however, requires their frequent application, since they are consumed by denitrifying bacteria at a rapid rate and are favored for nitrogen removal over more complex ones (Gomez et al. 2000, Hallin and Pell 1998, Peng et al. 2007). This is consistent with our finding that the microbial communities of low- and high-load beads obtained from RAS MBBs actively reduced nitrate in the presence of acetate and glucose at rates of between 1.5 to 2.8 times faster than those obtained for soluble or granular starches (Table 1). For the granular starches, comparable nitrate removal rates were initially obtained for both low- and high-load systems, although appearance of nitrate utilization in the high-load system in the presence of the granular starches occurred between 25 and 60 hours earlier than for the low-load beads (compare Figures 1A and 3A). The difference in timing is likely due to a variation in the composition and abundance of the bacterial communities in the two systems; the high-load biofilter beads originated from a RAS that included an active denitrification loop, providing a pool of bacterial denitrifiers (Tal et al. 2003, Tal et al. 2006). Enrichment of bacterial denitrifiers and/or stimulation of their activities after the first application of nitrate for both low- and high-load beads would also explain the appearance of nitrate removal shortly after addition of both the second and third nitrate doses for both soluble and granular starches.

Once nitrate consumption began, nitrate removal rates in the presence of granular starches were comparable for both low- and high-load beads (Table 1), and were similar to the rates observed for soluble starch in the low-load system (Table 1). After complete consumption of the initial nitrate dose by the low-load beads, reapplication of nitrate demonstrated that beads supplemented with granular starch maintained 
their denitrification potential, whereas those provided with soluble starch lacked this additional activity. Interestingly, while the $\mathrm{C}: \mathrm{N}$ ratio of the soluble starch incubations in the low-load system was approximately similar to that of the granular starches, soluble starch was only capable of supporting a third of the total nitrate reduction measured (by mass) for the granular starches. This difference might be explained by the contribution of non-denitrifying, starch-hydrolyzing Bacillus spp. (Morrison, Tal and Schreier, unpublished; Tal et al. 2003) present within the microbial consortia of the biofilter system. As TAC measurements were not able to detect any significant carbohydrate levels after the initial consumption of nitrate, it is conceivable that the ability to utilize subsequent additions of nitrate was due to either slow solubilization and/or hydrolysis of carbohydrates from granular starch particles trapped within beads, or immediate metabolism by the bacteria coating starch particles, thereby enhancing the efficiency of starch utilization for denitrification. The varying particle sizes for the three granular starches used in this study may influence their ability to be metabolized by heterotrophic bacteria; corn, rice, and wheat starches have diameters of 5-20 $\mu \mathrm{m}, 2-6 \mu \mathrm{m}$, and a mixture of 5-10 $\mu \mathrm{m}$ and 20-50 $\mu \mathrm{m}$, respectively (International Starch Institute, Aarhus, Denmark). Whether starch utilization could take place in the absence of nitrate was not examined.

While the effect of soluble starch on nitrate removal was not examined using the high-load beads, we found that glucose stimulated nitrate removal activity at the same rate and at approximately the same time as acetate through the first and second doses of nitrate. However, in the presence of acetate, nitrate removal rates decreased 12.4-fold (Table 1) after the third application of nitrate, presumably due to rapid exhaustion of the three-carbon acetate in a manner that was physiologically different from the six-carbon glucose. Glucose, on the other hand, continued to stimulate nitrate removal after the second and third nitrate applications at rates similar to the initial loading of nitrate. Since glucose is a primary product of starch hydrolysis, it follows that nitrate removal rates for the granular starch incubations may be similar to those observed for the glucose-supplemented tubes, provided that the level of glucose released upon granular starch solubilization and hydrolysis was not limiting. Indeed, aside from the first nitrate application, removal rates for all three granular starches by the high-load beads were identical to those obtained for glucose (Table 1). For the initial nitrate application, the delay and slow 
removal rates in the presence of the granular starches (1.8- to 2.8-fold lower compared to glucose) could be explained by low starch-degrading and solubilizing activities necessary for supplying an electron source to promote nitrate reduction; once the effective glucose concentration released by starch solubilization and hydrolysis increased, nitrate removal rates approached those obtained for glucose.

For both low- and high-load bead experiments, nitrite levels were found to gradually accumulate after nitrate addition, reaching their highest levels shortly after nitrate removal was detected; these levels began to decrease coincidental to, or shortly after, the corresponding drop in nitrate levels. Nitrite accumulation often occurs as a consequence of both incomplete reduction of nitrate to nitrogen gas and competition between various nitrate and nitrite reductases for common electron donors. The carbon source used for growth are likely occurring within the complex microbial communities associated with the biofilms in these bead systems (Blaszczyk 1993, Wilderer et al. 1987). Furthermore, accumulation of nitrite can also be attributed to localized variations in $\mathrm{pH}$ across the biofilm in individual beads or between sectors of beads (Almeida et al. 1995), or the presence of oxygen (Betlach and Tiedje 1981, van Rijn and Rivera 1990) that may have been introduced during sample handling. While our studies were not able to address the precise effects of nitrite and other denitrification intermediates $\left(\mathrm{NO}\right.$ and $\mathrm{N}_{2} \mathrm{O}$ ) on nitrate reduction in detail, both nitrate and nitrite were effectively removed by the low- and high-load bead systems, with glucose and granular starches providing a continued source of reducing power. As these carbon sources were provided in excess (as evidenced by complete removal of nitrite) they were available for use by the bead microbial communities, suggesting that their ability to promote nitrate reduction proceeds towards the production of elemental nitrogen, i.e. via the denitrification route. Since ammonia accumulation was not measured, we are not able to rule out the possibility that dissimilatory nitrate reduction may be playing some role under these conditions (van Rijn et al. 2006).

In summary, our results indicated that granular starches were effective in fueling biological denitrification and appear to behave as "slow-release" carbon sources. The process of applying granular starch in an up-flow fixed-bed biofilter using polyethylene beads as a substrate for bacterial growth, and employing a retaining mechanism for the granular starch, 
is simple and cost-effective. Many studies on wastewater treatment have focused on using mixed liquor or even introducing a granular polymer such as polyhydroxybutyrate, a constituent of sludge, as an external carbon source to stimulate denitrification (Anderson and Dawes 1990, Dionisi et al. 2004, Qin et al. 2005). As these alternatives are costly and require an additional dosing mechanism, we suggest that there is both an economical and practical advantage to using granular starch to stimulate denitrification. Furthermore, the characteristic low solubility of granular starch may contribute to a predictable and stable denitrifying environment and should prove beneficial in selecting the most appropriate form of starch for a RAS. We have found that supplementing a denitrification unit attached to a large-scale intensive closed marine RAS with granular starch was an effective approach for stimulating denitrification activity and maintaining minimal nitrate accumulation within the culture tank (Tal and Schreier, unpublished). Addition of granular starch to an upflow fixed-bed biofilter in a ratio of 1:20 (starch to fish feed) every seven days successfully promoted nitrate reduction in filter water and overall low nitrate concentrations in the fish tanks with maximum fish densities of $50-60 \mathrm{~kg} / \mathrm{m}^{3}$ (Tal and Schreier, unpublished). The low cost, ease of usability, and non-toxic nature of granular starch, therefore, make it an ideal exogenous carbon source to stimulate nitrate waste removal in RAS denitrification bioreactors.

\section{ACKNOWLEDGEMENTS}

We thank Steve Rodgers, Eric Evans and the staff of the Center of Marine Biotechnology's Aquaculture Research Center for their assistance in this research. This work was funded, in part, by the Living Marine Resources Cooperative Sciences Center (LMRCSC) of NOAA's Educational Partnership Program and Research Grant No. IS-3424-03 from BARD, the United States-Israel Binational Agricultural Research and Development Fund. Megan Morrison was a LMRCSC graduate fellow. This is manuscript number 05-125 from the Center of Marine Biotechnology at the University of Maryland, Baltimore, MD, USA. 


\section{REFERENCES}

Almeida, J.S., Reis, M.A.M., and Carrondo, M.J.T. Competition Between Nitrate and Nitrite Reduction in Denitrification by Pseudomonas fluorescens. Biotechnology and Bioengineering 1995, 46:476484.

Anderson, A.J and Dawes, E.A. Occurrence, Metabolism, Metabolic Role, and Industrial Uses of Bacterial Polyhydroxyalkanoates. $\mathrm{Mi}$ crobiological Reviews 1990, 54:450-472.

Arbiv, R. and van Rijn, J. Performance of a Treatment System for Inorganic Nitrogen Removal in Intensive Aquaculture Systems. Aquacultural Engineering 1995, 14:189-203.

Betlach, M.R. and Tiedje, J.M. Kinetic Explanation for Accumulation of Nitrite, Nitric Oxide, and Nitrous Oxide During Bacterial Denitrification. Applied and Environmental Microbiology 1981, 42:1074-1084.

Blaszczyk, M. Effect of Medium Composition on the Denitrification of Nitrate by Paracoccus denitrificans. Applied and Environmental Microbiology 1993, 59:3951-3953.

Burgess, P.J. Marine Whitespot Disease. Freshwater and Marine Aquaculture 1995, 18:168-196.

Chen, S.K., Juaw, C.K., and Cheng, S.-S. Nitrification and Denitrification of High-Strength Ammonium and Nitrite Wastewater with Biofilm Reactors. Water Science and Technology 1991, 23:1417-1425.

Costa-Pierce, B. and Desbonnet, A. A Future Urban Ecosystem Incorporating Urban Aquaculture for Wastewater Treatment and Food Production. In Urban Aquaculture 2005. Costa-Pierce, B., Desbonnet, A., Edwards, P., Baker, D. (Eds.). CABI Publishing: Cambridge, MA, USA, 1-14.

Cytryn, E., Gelfand, I., Barak, Y., van Rijn, J., and Minz, D. Diversity of Microbial Communities Correlated to Physiochemical Parameters in a Digestion Basin of a Zero-Discharge Mariculture System. Environmental Microbiology 2003, 5:55-63. 
Dionisi, D., Renzi, V., Majone, M., Beccari, M., and Ramadori, R. Storage of Substrate Mixtures by Activated Sludges Under Dynamic Conditions in Anoxic or Aerobic Environments. Water Research 2004, 38:2196-2206.

Glass, C. and Silverstein, J. Denitrification on High-Nitrate High-Salinity Wastewater. Water Research 1999, 33:223-229.

Gomez, M.A., Gonzalez-Lopez, J., and Hontoria-Garcia, E. Influence of Carbon Source on Nitrate Removal of Contaminated Groundwater in a Denitrifying Submerged Filter. Journal of Hazardous Materials B 2000, 80:69-80.

Grguric, G., Wetmore, S.S., and Fournier, R.W. Biological Denitrification in a Closed Seawater System. Chemosphere 2000, 40:549-555.

Hallin, S. and Pell, M. Metabolic Properties of Denitrifying Bacteria Adapting to Methanol and Ethanol in Activated sludge. Water Research 1998, 32:13-18.

Her, J.J. and Huang, J.S. Influences of Carbon Source and C/N ratio on Nitrate/Nitrite Denitrification and Carbon Breakthrough. Bioresearch and Technology 1995, 54:45-51.

Hrubec, T.C., Smith, S.A., and Robertson, J.L. Nitrate Toxicity: a Potential Problem of Recirculating Systems. In Proceedings from the Successes and Failures in Commercial Recirculating Aquaculture Conference 1996. Libey, G.S. and Timmons, M.B. (Eds.) Northeast Regional Agricultural Engineering Service: Ithaca, NY, USA, 41-48.

Isaacs, S., Henze, M., Soeberg, H., and Kummel, M. External Carbon Source Addition as a Means to Control an Activated Sludge Nutrient Removal Process. Water Research 1994, 28, 511-520.

Labelle, M.-A., Juteaub, P., Jolicoeurc, M., Villemurb, R., Parentd, S., and Comeau, Y. Seawater Denitrification in a Closed Mesocosm by a Submerged Moving Bed Biofilm Reactor. Water Research 2005, 39:3409-3417.

Lee, N.M. and Welaner, T. The Effect of Different Carbon Sources on Respiratory Denitrification in Biological Wastewater Treatment. Journal of Fermentation and Bioengineering 1996, 82, 277-285. 
Mycielski, R., Blaszczyk, M., Jackowska, A., and Olkowska, H. Denitrification of High Concentrations of Nitrites and Nitrates in Synthetic Medium with Different Sources of Organic Carbon. II. Ethanol. Acta Microbiologica Polonica 1983, 32:381-388.

Peng, Y.-Z., Yong, M.A., and Wang, S.-Y. Denitrification Potential Enhancement by Addition of External Carbon Sources in a Pre-Denitrification Process. Journal of Environmental Science 2007, 19:284289.

Phillips, J.B. and Love, N.G. Biological Denitrification Using Upflow Biofiltration in Recirculating Aquaculture Systems: Pilot-Scale Experience and Implications for Full-scale. In Proceedings of the Second International Conference on Recirculating Aquaculture 1998. Virginia Polytechnic Institute and State University: Roanoke, VA, USA, 171-178.

Prinsloo, J.F., Roets, W., Theron, J., Hoffman, L.C., and Schoonbee, H.J. Changes in Some Water Quality Conditions in Recycling Water Using Three Types of Biofiltration Systems During the Production of the Sharptooth Catfish Clarias gariepinus (Burchell). Water SA 1999, 25:239-252.

Qin, L., Liu, Y., and Tay, J.-H. Denitrification on Poly-ß-hydroxybutyrate in Microbial Granular Sludge Sequencing Batch Reactor. Water Research 2005, 39:1503-1510.

Stief, P. Influence of Sediment and Pore-Water Composition on Nitrite Accumulation in a Nitrate-Perfused Freshwater Sediment. Water Research 2001, 35:2811-2818.

Tal, Y., van Rijn, J., and Nussinovitch, A. Improvement of Mechanical and Biological Properties of Freeze-Dried Denitrifying Alginate Beads by Using Starch as a Filter and Carbon Source. Applied and Environmental Biotechnology 1999, 51:773-779.

Tal, Y., Watts, J.E., Schreier, S.B., Sowers, K.R., and Schreier, H.J. Characterization of the Microbial Community and Nitrogen Transformation Processes Associated with Moving Bed Bioreactors in Closed Recirculated Mariculture Systems. Aquaculture 2003, 215:187-202. 
Tal, Y., Watts, J.E., and Schreier, H.J. Anaerobic Ammonium-Oxidizing (Anammox) Bacteria and Associated Activity in Fixed-Film Biofilters of a Marine Recirculating Aquaculture System. Applied and Environmental Microbiology 2006, 72:2896-2904.

Tal, Y., Schreier, H.J., Sowers, K.R., Stubblefield, J.D., Place, A.R., and Zohar, Y. Environmentally Sustainable Land-Based Marine Aquaculture. Aquaculture 2009, 286:28-35.

Timmons, M.B., Ebeling, J.M., Wheaton, F.W., Summerfelt, S.T., and Vinci, B.J. 2002. Recirculating Aquaculture Systems. Cayuga Aqua Ventures: Ithaca, NY, USA,

van Rijn, J. and Rivera G. Aerobic and Anaerobic Biofiltration in an Aquaculture Unit-Nitrite Accumulation as a Result of Nitrification and Denitrification. Aquacultural Engineering 1990, 9:217-234.

van Rijn, J. The Potential for Integrated Biological Treatment Systems in Recirculating Fish Culture--A Review. Aquaculture 1996, 139:181201.

van Rijn, J., Tal, Y., and Schreier, H.J. Denitrification in Recirculating Systems: Theory and Applications. Aquacultural Engineering 2006, 34:364-376.

White, K., O'Neill, B.N., and Tzankova, Z., 2004. At a Crossroads: Will Aquaculture Fulfill the Promise of the Blue Revolution? SeaWeb Aquaculture Clearinghouse: Washington, DC, USA.

Wilderer, P.A., Jones, W.L., and Dau, U. Competition in Denitrification Systems Affecting Reduction Rate and Accumulation of Nitrite. Water Research 1987, 21:239-245.

Zohar, Y., Tal, Y., Schreier, H.J., Steven, C.R., and Stubblefield, J., Place A.R. Commercially Feasible Urban Recirculating Aquaculture: Addressing the Marine Sector. In Urban Aquaculture 2005. CostaPierce, B., Desbonnet, A., Edwards, P., Baker, D. (Eds.). CABI Publishing: Cambridge, MA, USA, 159-171. 